\title{
Thermoelectric performance of films in the bismuth-tellurium and antimony-tellurium systems
}

\author{
Luciana W. da Silva, ${ }^{\text {a) }}$ Massoud Kaviany, ${ }^{\text {b) }}$ and Ctirad Uher ${ }^{\mathrm{c})}$ \\ University of Michigan, Ann Arbor, Michigan 48109
}

(Received 10 December 2004; accepted 23 March 2005; published online 24 May 2005)

\begin{abstract}
Coevaporated bismuth-tellurium and antimony-tellurium films were fabricated under various deposition conditions (controlled evaporation rates of individual species, substrate temperature, and substrate material), and their thermoelectric (TE) properties (Seebeck coefficient, electrical resistivity, and carrier concentration) were measured in search of optimal TE performance. The tellurium atomic concentration was varied from $48 \%$ to $74 \%$, the substrate temperature ranged from 130 to $300{ }^{\circ} \mathrm{C}$, and glass, mica, magnesium oxide, and sapphire substrates were used. The chemical composition and crystal structure of the films were recorded (using microprobe and $\mathrm{x}$-ray diffractometer, respectively), analyzed, and compared with available standard $\mathrm{Bi}_{2} \mathrm{Te}_{3}$ and $\mathrm{Sb}_{2} \mathrm{Te}_{3}$ single-crystal samples. High-performance TE films had tellurium atomic concentration around $60 \%$ and were deposited at a substrate temperature between 260 and $270{ }^{\circ} \mathrm{C}$. (C) 2005 American Institute of Physics. [DOI: 10.1063/1.1914948]
\end{abstract}

\section{INTRODUCTION}

Telluride compounds have been extensively studied in the past decades, due to their high thermoelectric (TE) figure of merit $Z_{e}$ at room temperature. In bulk materials, a dimensionless figure of merit $Z_{e} T$ of 0.75 in $p-\mathrm{BiSb}_{2} \mathrm{Te}_{3}$, at $300 \mathrm{~K}$, was reported about 40 years ago. ${ }^{1}$ Since then, there has been modest progress in increasing $Z_{e} T$ near room temperature. The highest value reported appears to be 1.14 for the $p-\left(\mathrm{Bi}_{2} \mathrm{Te}_{3}\right)_{0.25}\left(\mathrm{Sb}_{2} \mathrm{Te}_{3}\right)_{0.72}\left(\mathrm{Sb}_{2} \mathrm{Se}_{3}\right)_{0.03}$ alloy. ${ }^{2}$

The TE properties of telluride films $(0.7-20 \mu \mathrm{m}$ thick $)$ measured at room temperature, for various deposition methods, substrate temperatures, and substrate materials, are listed in Fig. 1. Zou et al. ${ }^{3}$ deposited $n-\mathrm{Bi}_{2} \mathrm{Te}_{3}$ and $p-\mathrm{Sb}_{2} \mathrm{Te}_{3}$ films by coevaporation, at a substrate temperature $T_{\text {sub }}$ of 260 and $230{ }^{\circ} \mathrm{C}$, respectively, with $Z_{e} T$ of approximately 0.3 (thermal conductivity of $1.5 \mathrm{~W} / \mathrm{m} \mathrm{K}$ is assumed). Lim et al. ${ }^{4}$ used electroplating, and the $n-\mathrm{Bi}_{2} \mathrm{Te}_{3}$ films exhibited notably low performance, compared with that reported by others. The properties of the $p-\mathrm{Bi}_{2-x} \mathrm{Sb}_{x} \mathrm{Te}_{3}$ films were not fully characterized due to the poor reproducibility. Böttner $e t$ $a l .{ }^{5,6}$ used cosputtering, followed by annealing, to improve the TE properties.

Several approaches have been proposed to enhance $Z_{e} T$ in thin-film TE materials. Using quantum-confinement effects, which allows for the manipulation of the Seebeck coefficient $\alpha_{S}$ by enhancing the density of states near the Fermi energy, $Z_{e} T$ ranging from 1.3 to 1.6 , at $300 \mathrm{~K}$, was reported for $\mathrm{PbSeTe} / \mathrm{PbTe}$ quantum dot superlattice structures. ${ }^{7,8}$ Venkatasubramanian et al. ${ }^{2}$ show $Z_{e} T$ of 2.4 for $p$-type nanostructured superlattices of $\mathrm{Bi}_{2} \mathrm{Te}_{3} / \mathrm{Sb}_{2} \mathrm{Te}_{3}$ at room temperature. These are phonon-blocking/electron-transmitting super-

\footnotetext{
${ }^{a)}$ Department of Mechanical Engineering; electronic mail: ldasilva@umich.edu

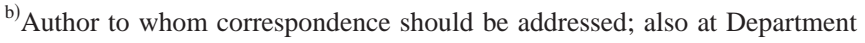
of Mechanical Engineering; electronic mail: kaviany@umich.edu

c)Department of Physics; electronic mail: cuher@umich.edu
}

lattices, which are produced by alternately depositing thin (1-4 nm) films of $\mathrm{Bi}_{2} \mathrm{Te}_{3}$ and $\mathrm{Sb}_{2} \mathrm{Te}_{3}$. For $n$-type $\mathrm{Bi}_{2} \mathrm{Te}_{3} / \mathrm{Bi}_{2} \mathrm{Te}_{2.83} \mathrm{Se}_{0.17}, Z_{e} T$ of 1.4 is found. Exploring thermionic emission at interfaces, Vashaee and Shakouri ${ }^{9}$ have recently shown that metal-base superlattices with tall barriers can achieve $Z_{e} T$ larger than 5, at room temperature. A key requirement is the nonconservation of lateral momentum, which allows a higher number of electrons to participate in the thermionic emission process.

The motivation for the present work is the application of $\mathrm{Bi}_{2} \mathrm{Te}_{3}$ and $\mathrm{Sb}_{2} \mathrm{Te}_{3}$ (in their simplest form) as the $n$ - and $p$-type elements, respectively, of a column-type micro-TE cooler. ${ }^{10}$ Using coevaporation of the elements, we deposited bismuth-tellurium (Bi-Te) and antimony-tellurium ( $\mathrm{Sb}-\mathrm{Te})$ thin films at various $T_{\text {sub }}$ and compositions, seeking films with optimum TE performance. Although it is known that $T_{\text {sub }}$ above $200{ }^{\circ} \mathrm{C}$ is needed for films with high $Z_{e} T$ (or high power factor $\alpha_{S}^{2} / \rho_{e}$, as reported in Fig. 1), the performance of telluride compound films formed at lower temperatures is also investigated, since in the device fabrication, the current TE film patterning method limits $T_{\text {sub }}$ to values below $170{ }^{\circ} \mathrm{C}^{11}$ The effect of substrate material and crystal structure on the TE properties is also explored. Platinum is used as the substrate for the TE films in the micro-TE cooler fabrication (current is injected through metal connectors composed of $\mathrm{Cr} / \mathrm{Au} / \mathrm{Ti} / \mathrm{Pt}$ layers, where $\mathrm{Pt}$ interfaces with the TE elements), ${ }^{11}$ and so, it is of particular interest here.

\section{FILM FABRICATION}

The Bi-Te and $\mathrm{Sb}-\mathrm{Te}$ films were deposited by coevaporation. Each of the elements $(\mathrm{Bi}, \mathrm{Sb}$, and $\mathrm{Te}$ shots are 99.999\% pure) of the desired compound (from the Bi-Te or $\mathrm{Sb}-\mathrm{Te}$ systems) is placed in a 17-cc molybdenum boat, which is connected to an independent power supply (controlled manually). The flux from each source is monitored with separate quartz-crystal sensors. The substrates are placed at a distance of $46 \mathrm{~cm}$ above the sources, and rotate at 


\begin{tabular}{|l|l|l|l|l|l|l|}
\hline Reference & \multicolumn{2}{|c|}{ Zou et al. [3] } & \multicolumn{2}{c|}{ Lim et al. [4] } & \multicolumn{2}{c|}{ Böttner et al. [5, 6] } \\
\hline Fabrication Method & Co-Evaporation & \multicolumn{2}{c|}{ Electroplating } & \multicolumn{2}{c|}{ Co-Sputtering } \\
\hline Substrate Material & \multicolumn{2}{|c|}{ Glass } & \multicolumn{2}{c|}{$\mathrm{Au}$} & \multicolumn{2}{c|}{$\mathrm{N} / \mathrm{R}$} \\
\hline TE Film Material & $\begin{array}{l}p- \\
\mathrm{Sb}_{2} \mathrm{Te}_{3}\end{array}$ & $\begin{array}{l}n- \\
\mathrm{Bi}_{2} \mathrm{Te}_{3}\end{array}$ & $\begin{array}{l}p- \\
\mathrm{Bi}_{2-\mathrm{x}} \mathrm{Sb}_{\mathrm{x}} \mathrm{Te}_{3}\end{array}$ & $\begin{array}{l}n- \\
\mathrm{Bi}_{2} \mathrm{Te}_{3}\end{array}$ & $\begin{array}{l}p- \\
\left(\mathrm{Bi}, \mathrm{Sb}_{2} \mathrm{Te}_{3}\right.\end{array}$ & $\begin{array}{l}n- \\
\mathrm{Bi}_{2} \mathrm{Te}_{3}\end{array}$ \\
\hline Substrate Temperature, $T_{\text {sub }}\left({ }^{\circ} \mathrm{C}\right)$ & 230 & 260 & $\mathrm{~N} / \mathrm{A}$ & $\mathrm{N} / \mathrm{A}$ & $\mathrm{N} / \mathrm{R}$ & $\mathrm{N} / \mathrm{R}$ \\
\hline Seebeck coefficient, $\alpha_{\mathrm{S}}(\mu \mathrm{V} / \mathrm{K})$ & 171 & -228 & $\mathrm{~N} / \mathrm{R}$ & -60 & 227 & -155 \\
\hline Electrical resistivity, $\rho_{e}(\mu \Omega-\mathrm{m})$ & 10.4 & 13.0 & $\mathrm{~N} / \mathrm{R}$ & 10.0 & 23 & 21 \\
\hline Power factor, $\alpha_{s}{ }^{2} / \rho_{e}\left(\mathrm{~mW} / \mathrm{K}{ }^{2}-\mathrm{m}\right)$ & 2.80 & 3.99 & $\mathrm{~N} / \mathrm{R}$ & 0.36 & 2.24 & 1.14 \\
\hline Film thickness, $L_{t e}(\mu \mathrm{m})$ & 0.7 & 0.7 & 20 & 20 & $10-20$ & $10-20$ \\
\hline
\end{tabular}

FIG. 1. Reported deposition methods and properties of the $n$ - and $p$-type telluride films. (N/A: Not/Available; N/R: Not/Reported). a controlled speed. A resistive heater (placed above the substrate) can maintain a constant substrate temperature of up to $300{ }^{\circ} \mathrm{C}$, which is measured by a type- $K$ thermocouple located at a distance of $5 \mathrm{~mm}$ from the substrate edge. The calibration of this thermocouple was established by comparing its temperature with a second thermocouple attached directly at the back surface of the substrate, which was stationary. An additional film thickness monitor is used to measure the overall thickness of the deposited compound.

The pressure during deposition varied from $1 \times 10^{-6}$ to $4 \times 10^{-6}$ torr. The $\mathrm{Bi}$ and $\mathrm{Sb}$ deposition rates varied from $1 \pm 0.1$ to $2.5 \pm 0.1 \AA / \mathrm{s}$, while the Te rate varied from $2.5 \pm 0.5$ to $4.5 \pm 0.5 \AA / \mathrm{s}$. All substrates were cleaned prior to the deposition with acetone and isopropanol, and dried with $\mathrm{N}_{2}$.

\section{FILM CHARACTERIZATION}

\section{A. Crystal structure and composition}

The microstructure of the films (grain size and orientation) was examined using a high-resolution scanning electron microscope (SEM), which is combined with a focussed ionbeam workstation. The latter was used for in situ preparation and analysis of sample cross sections. In order to prevent the damage to the surface grains by the ion beam, a platinum patch (1 $\mu \mathrm{m}$ thick) was deposited on top of each TE film, prior to the sectioning.

The orientation of the crystals in the films was determined from x-ray diffraction (XRD) analyses. The patterns were obtained using a Scintag powder x-ray diffractometer.

The relative concentration of the elements was measured, with an accuracy of $\pm 2 \%$, by an electron microprobe analyzer, and averaged over ten distinct locations for each sample.

\section{B. Thermoelectric properties}

The Seebeck coefficient $\alpha_{S}$ was measured at room temperature, under vacuum. In each case, data were collected from two films deposited at the same time on identical substrates, which were mounted as shown in Fig. 2. One end of the film (10-20 mm long and 2-4 mm wide) was thermally connected to a heat sink and the other end to a heater. The temperatures of the hot and cold sides $\left(T_{h}\right.$ and $T_{c}$, respectively) were measured with fine copper-constantan thermo- couples. The $\mathrm{Cu}$ leads of the thermocouples were also used to measure the potential difference, $\Delta \varphi$, across the film. The Seebeck coefficient was determined by

$$
\alpha_{S}=\frac{\Delta \varphi}{T_{h}-T_{c}},
$$

and the results were corrected for the thermopower of the $\mathrm{Cu}$ leads.

The electrical resistivity $\rho_{e}$ was obtained using the standard four-probe method, also at room temperature, under vacuum. It is given by

$$
\rho_{e}=\frac{R_{e} A_{t}}{L}
$$

where $L$ is the film length (distance between the fine copper wires used for $\Delta \varphi$ measurement when an electrical current $J_{e}$ is applied), $A_{t}\left(=w L_{t e}\right.$, i.e., product between the width $w$ and the thickness $\left.L_{t e}\right)$ is the film cross-section area, and $R_{e}\left(=\Delta \varphi / J_{e}\right)$ is the electrical resistance. The film thickness, $L_{t e}$, was obtained from four different locations on the sample, with an accuracy of $\pm 5 \%$, using a surface profiler.

Hall-effect measurements were performed in a cryostat equipped with a superconducting $(5 \mathrm{~T})$ magnet. A magnetic field $B$ and current $J_{e}$ were applied, and $R_{e}$ (or $\Delta \varphi$ ) was measured. Data were taken in both magnetic-field directions to eliminate effects due to any probe misalignment. The Hall coefficient $R_{H}$ is given by

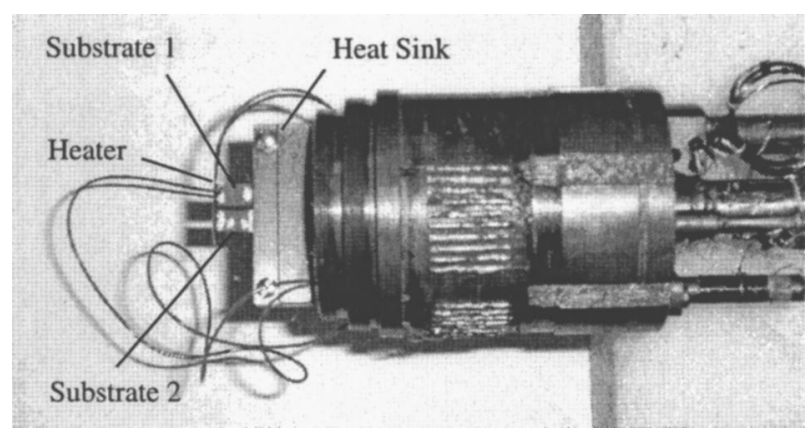

FIG. 2. Probe used for the Seebeck coefficient and electrical resistivity measurements. Two substrates, with the same TE film deposited on them, are held by the heat sink (cold side). The heater is attached to the opposite edge of the substrates (hot side). The electrical resistivity measurements are performed on substrate 2, while the Seebeck coefficient is obtained from both substrates. 
TABLE I. Uncertainties of the measured and calculated properties.

\begin{tabular}{cc}
\hline \hline & \\
Property & Uncertainty $(\%)$ \\
\hline$\alpha_{S}$ & \pm 5 \\
$\rho_{e}$ & \pm 12 \\
$\alpha_{S}^{2} / \rho_{e}$ & \pm 15 \\
$R_{H}$ & \pm 15 \\
$n_{c}$ & \pm 15 \\
$\mu$ & \pm 20 \\
\hline \hline
\end{tabular}

$$
R_{H}=R_{e} \frac{L_{t e}}{B},
$$

and from that, the carrier concentration $n_{c}$ and mobility $\mu$ were calculated using

$$
n_{c}=\frac{1}{R_{H} e_{c}} \text { and } \mu=\frac{R_{H}}{\rho_{e}},
$$

where $e_{c}$ is the electron charge.

\section{Error analysis}

The uncertainty $\Delta F$ of a property $F$ was calculated using the relation

$$
\Delta F\left(x_{1}, x_{2}, \ldots\right)=\left[\sum_{i=1}^{n}\left(\frac{\partial F}{\partial x} \Delta x_{i}\right)^{2}\right]^{1 / 2},
$$

where

$$
\begin{aligned}
F\left(x_{1}, x_{2}, \ldots\right) & =\alpha_{S}\left(\Delta \varphi, T_{h}, T_{c}\right) \\
& =\rho_{e}\left(R_{e}, w, L_{t e}, L\right) \\
& =\alpha_{S}^{2} / \rho_{e}\left(\alpha_{S}, \rho_{e}\right) \\
& =R_{H}\left(R_{e}, L_{t e}\right) \\
& =n_{c}\left(R_{H}\right) \\
& =\mu\left(R_{H}, \rho_{e}\right) .
\end{aligned}
$$

The results are shown in Table I.

For $\alpha_{S}$, which was obtained from two samples of the same film that were mounted side by side in the probe (Fig. 2 ), variations in repeatability were also taken into account. The Seebeck coefficient was measured on each sample after heating and waiting 20-30 min for steady state, and also after cooling. So, data were collected twice for each sample, totaling four measurements for each film. The difference between the maximum and minimum value of these four measurements was calculated in terms of a fraction of the averaged $\alpha_{S}$. This was compared with the result from Eq. (5), and the larger value was taken as the uncertainty in $\alpha_{S}$.

The accuracy of the $\rho_{e}$ was limited by the uncertainties in $A_{t}$ and $L$, while for $R_{H}$, the limit was found by drifts in $R_{e}$ (or $\Delta \varphi$ ). Measurements of $R_{H}$ were not completed when drifts were above $10 \%$, which limited the data collection to only few points in the Bi-Te system. The electrical contacts, which were made with silver paint, were suspected to be

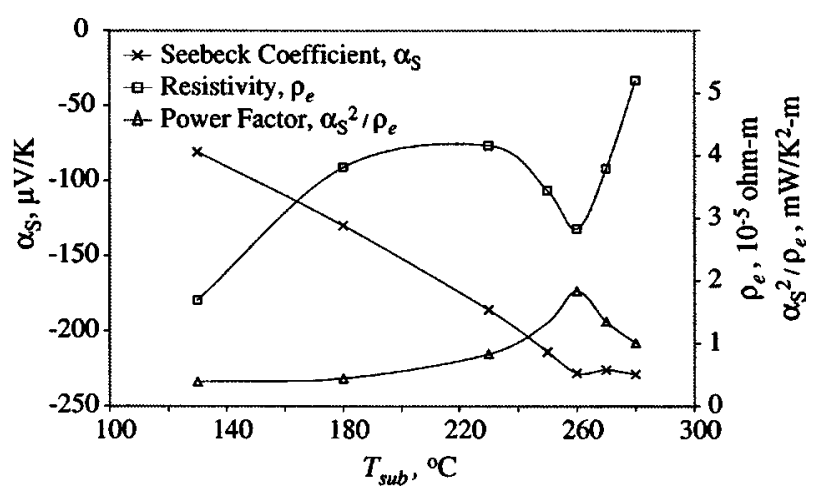

FIG. 3. Effect of $T_{\text {sub }}$ on the TE properties, where the Te concentration (averaged over ten points for each sample) varied from $59.7 \%$ to $60.9 \%$. (The lines are used only to guide the eye.)

causing this problem. Metallic $(\mathrm{Cu}$ or $\mathrm{Au})$ contacts can be patterned prior to or after the TE film deposition, for future measurements.

\section{OPTIMUM POWER FACTOR IN THE BISMUTH- TELLURIUM SYSTEM}

\section{A. Effect of substrate temperature on thermoelectric properties of $\mathrm{Bi}-\mathrm{Te}$ films}

One-micron-thick $\mathrm{Bi}-\mathrm{Te}$ films with $\mathrm{Te}$ concentration around $60 \%$ were deposited on a glass substrate at temperatures varying from 130 to $280^{\circ} \mathrm{C}$. In Fig. 3, the measured TE properties are shown for the various films. The Seebeck coefficient is negative indicating that the films are $n$-type, and its absolute value increases with $T_{\text {sub }}$ up to $260{ }^{\circ} \mathrm{C}$, where it reaches a plateau. Also, at this temperature $\rho_{e}$ has a minimum, and the power factor, $\alpha_{S}^{2} / \rho_{e}$, has its optimum value. At higher temperatures, because Te can reevaporate from the substrate leaving point defects (e.g., a vacancy or an antisite defect) in the crystal structure, $\rho_{e}$, which is sensitive to these defects, increases sharply.

The lower values of $\alpha_{S}$ at $T_{\text {sub }}<260{ }^{\circ} \mathrm{C}$ can be an indication that other $\mathrm{Bi}-\mathrm{Te}$ phases coexist with $\mathrm{Bi}_{2} \mathrm{Te}_{3}$. For pure $\mathrm{Bi}$ (although it is unlikely to find unreacted $\mathrm{Bi}$ in the films), $\alpha_{S}$ is -50 and $-100 \mu \mathrm{V} / \mathrm{K}$ for directions parallel and perpendicular to the trigonal axis, respectively. ${ }^{12}$ The film composition was measured at ten distinct locations on the sample, as previously mentioned, and for an analytical volume of about $1-2 \mu \mathrm{m}^{3}$, the at. \% Te varied from 59.3 to 60.1 , for the film deposited at $130{ }^{\circ} \mathrm{C}$. Although these values might indicate that the compound is $\mathrm{Bi}_{2} \mathrm{Te}_{3}$, they could be an average of various phases, since the area analyzed with the microprobe covers hundreds of grains for the lowtemperature film, as can be inferred from Fig. 4(a). The surface SEM micrograph of the film coevaporated at $260{ }^{\circ} \mathrm{C}$, with at. $\%$ Te of 60 , is shown in Fig. 4(b), where grains as large as $0.5 \mu \mathrm{m}$ are evident. The dashed lines at the crosssectional view are highlighting the grain boundaries. Voids are observed in the cross section of the film deposited at $130{ }^{\circ} \mathrm{C}$ [Fig. 4(a)], and the grain boundaries, although appearing to be closer to each other than in the higher $T_{\text {sub }}$ films, are not well defined. 
(a)

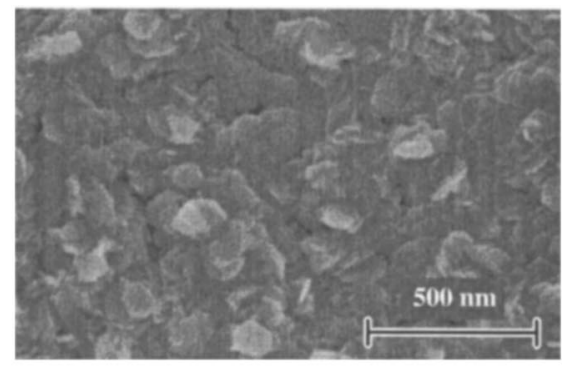

(b)

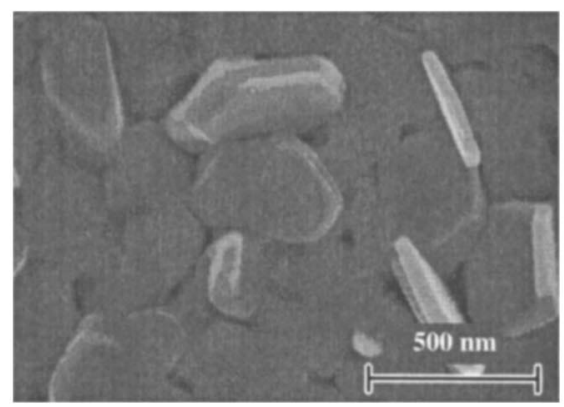

(c)

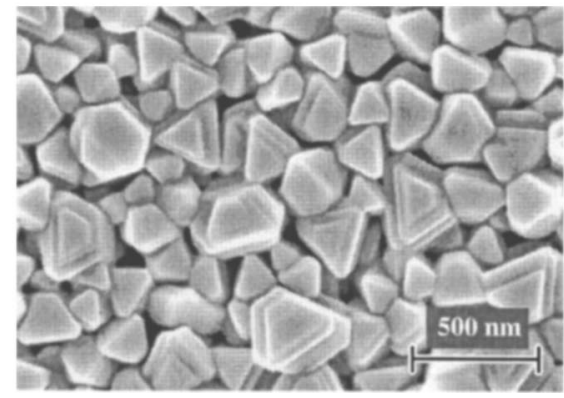

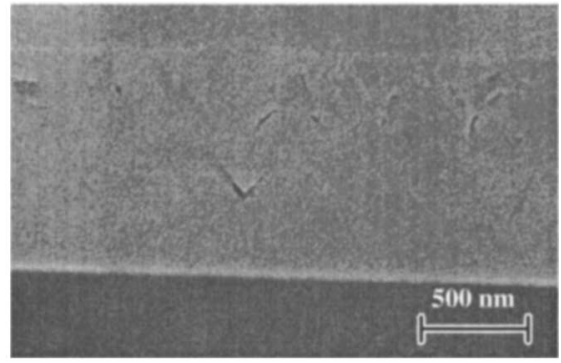
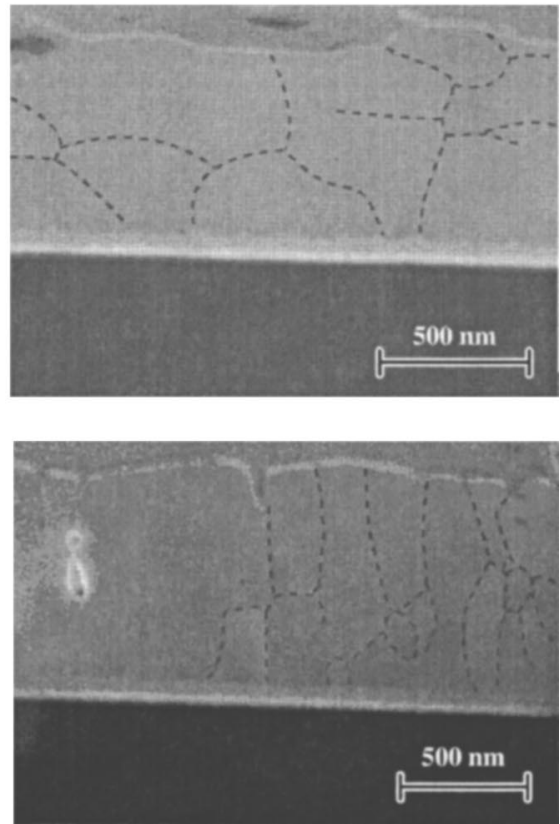

FIG. 4. SEM micrograph showing the top and cross section of the coevaporated $\mathrm{Bi}_{2} \mathrm{Te}_{3}$ films deposited at (a) 130 and (b) $260{ }^{\circ} \mathrm{C}$, both with at. $\% \mathrm{Te}$ of 60 , and (c) $260{ }^{\circ} \mathrm{C}$ with at. \% Te of 54. The bar on the bottom right of each SEM micrograph corresponds to a length of $500 \mathrm{~nm}$ (on scale). In (b) and (c), the dashed lines at the crosssection views are highlighting grain boundaries.
In Table II, $R_{H}, n_{c}$, and $\mu$ are presented for films deposited at $T_{\text {sub }}$ of 250,260 , and $280{ }^{\circ} \mathrm{C}$. Among the films with $60 \%$ of $\mathrm{Te}$, the one deposited at $260{ }^{\circ} \mathrm{C}$, which has the highest power factor, also has the highest mobility (presumably because it is very close to a true $\mathrm{Bi}_{2} \mathrm{Te}_{3}$ stoichiometry and thus has a minimal number of defects). High mobilities are expected for crystal structures with large grain sizes since they tend to reduce boundary scattering of carriers.

The diffraction patterns of powdered $\mathrm{Bi}_{2} \mathrm{Te}_{3}$ single crystal, and of the Bi-Te films, are shown in Figs. 5(a)-5(c). The position of the peaks agrees with the associated entries in the Powder-Diffraction File for $\mathrm{Bi}_{2} \mathrm{Te}_{3},{ }^{13}$ and the corresponding reflection planes $(h k l)$ are labeled.

The three highest relative intensities, $I / I_{o}$, reported in Ref. 13, correspond to the planes (015) $\left(I / I_{o}=100\right),(1.0 .10)$ $\left(I / I_{o}=25\right)$, and (110) $\left(I / I_{o}=25\right)$. For other peaks $I / I_{o} \leqslant 8$.

TABLE II. Measured Hall coefficient $R_{H}$, carrier concentration $n_{c}$, and mobility $\mu$ of $\mathrm{Bi}-\mathrm{Te}$ films, at room temperature.

\begin{tabular}{ccccc}
\hline \hline$T_{\text {sub }}\left({ }^{\circ} \mathrm{C}\right)$ & at. \% Te & $R_{H}\left(10^{-6} \mathrm{~m}^{3} / \mathrm{C}\right)$ & $n_{c}\left(10^{25} \mathrm{~m}^{-3}\right)$ & $\mu\left(10^{-4} \mathrm{~m}^{2} / \mathrm{V} \mathrm{s}\right)$ \\
\hline 250 & 60 & -0.063 & 9.9 & 2 \\
260 & 60 & -0.355 & 1.8 & 125 \\
280 & 60 & -0.270 & 2.3 & 52 \\
260 & 59.7 & -0.017 & 37 & 2.9 \\
260 & 57.6 & -0.006 & 96 & 9.6 \\
260 & 54.0 & -0.003 & 196 & 10.6 \\
\hline \hline
\end{tabular}

Note in Fig. 5 that these three strongest peaks are seen in the spectra of the reference-powdered $\mathrm{Bi}_{2} \mathrm{Te}_{3}$ (a) and of the films deposited at $130{ }^{\circ} \mathrm{C}$ (b) (the relative intensities are different). These reflection planes indicate no preferential crystallite orientation of samples (a) and (b), which was expected for (a), since the powdered grains are randomly oriented. We tried to match the $\mathrm{x}$-ray spectra of other possible phases (apart for $\mathrm{Bi}_{2} \mathrm{Te}_{3}$ ) within the $\mathrm{Bi}-\mathrm{Te}$ system but found no convincing match.

The intensities of the diffraction peaks corresponding to $(00 l)$ planes ( $c$-axis preferentially oriented, perpendicular to the substrate surface) become significant at $T_{\text {sub }}$ of $230{ }^{\circ} \mathrm{C}$ (not shown here), and increase at higher temperatures. They are dominant in the film deposited at $260^{\circ} \mathrm{C}$ [Fig. 5(c), peaks corresponding to (006) and (0.0.15) planes], which had the highest power factor (Fig. 3).

In Fig. 6, the diffraction patterns of the $\mathrm{Bi}-\mathrm{Te}$ films deposited at 130 and $260{ }^{\circ} \mathrm{C}$ are enlarged to show the effect of $T_{\text {sub }}$ on the linewidth of the peaks. The smaller linewidths observed in Fig. 6(b), when compared with (a), indicate an increase in the grain size with the increase of $T_{\text {sub}}$, and suggest higher crystalline quality. This result is in agreement with Figs. 4(a) and 4(b). Such physical characteristic of the films can also be affecting the TE properties (as previously discussed for mobility). 


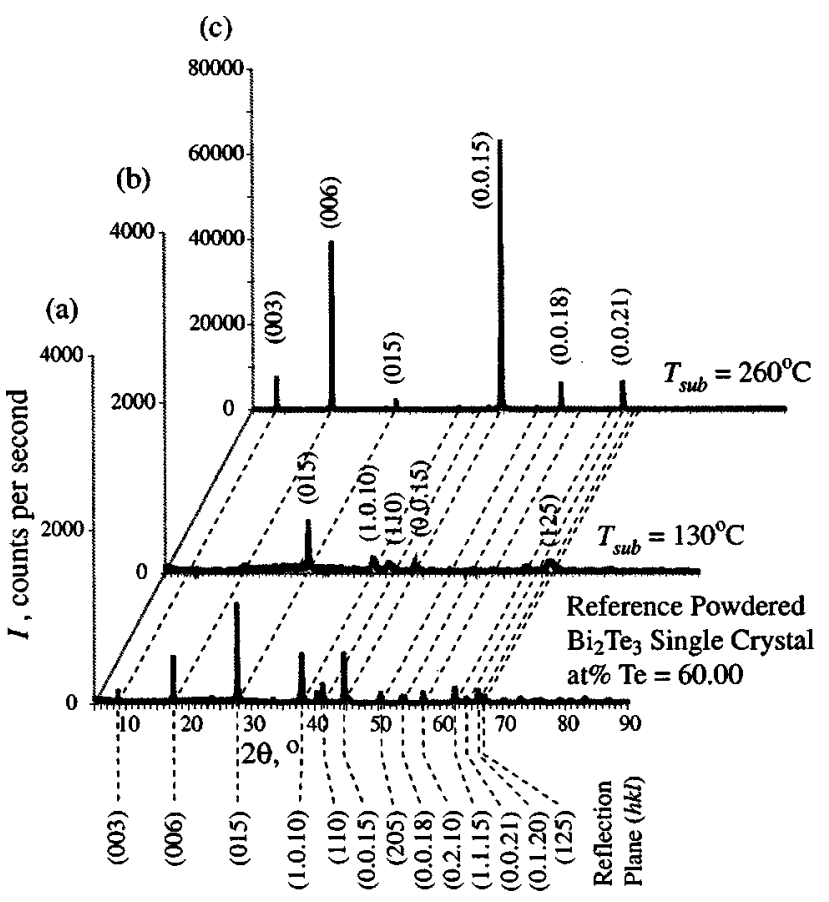

FIG. 5. X-ray diffraction patterns of reference-powdered $\mathrm{Bi}_{2} \mathrm{Te}_{3}$ single crystal (a), and coevaporated $\mathrm{Bi}_{2} \mathrm{Te}_{3}$ films (at. \% $\mathrm{Te} \sim 60$ ) deposited on a glass substrate at $130{ }^{\circ} \mathrm{C}(\mathrm{b})$, and at $260^{\circ} \mathrm{C}(\mathrm{c})$. The positions (diffraction angle $2 \theta$ ) of the measured peaks agree with the Powder-Diffraction File (see Ref. $13)$.

\section{B. Effect of film composition on thermoelectric properties of $\mathrm{Bi}-\mathrm{Te}$ films}

$\mathrm{Bi}-\mathrm{Te}$ films were deposited on glass substrates at various stoichiometries for $T_{\text {sub }}$ of 260 and $130{ }^{\circ} \mathrm{C}$. The effect of film composition on the TE properties can be seen, at these temperatures, in Figs. 7(a) and 7(b). The optimum power factors, given in Table III for both $T_{\text {sub }}$, were found for at. \% Te of approximately 60. Note that in Fig. 7(a), films with at. \% $\mathrm{Te}>60$ could not be obtained due to the reevaporation of $\mathrm{Te}$ from the substrate.

In the XRD patterns (not presented here), no effect of composition on the predominant orientation of the films

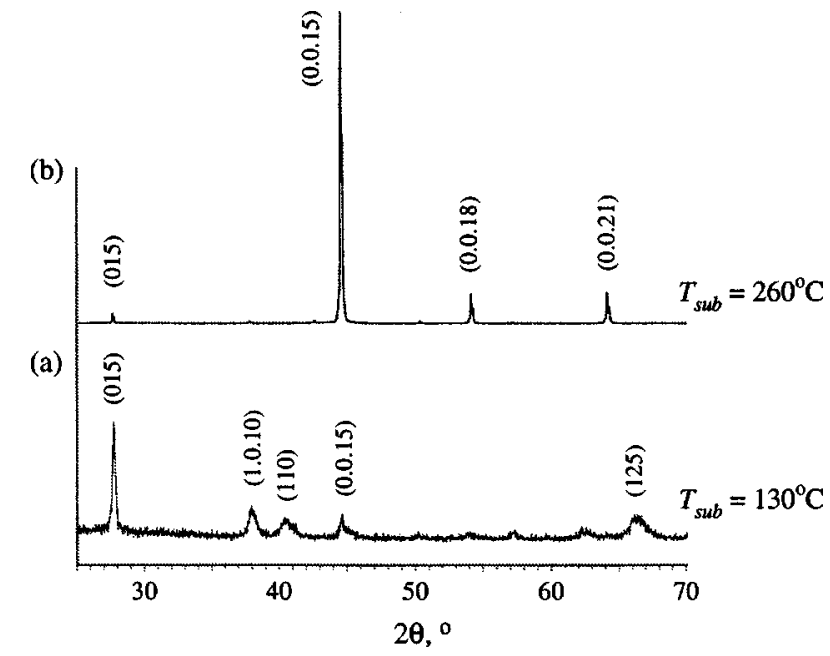

FIG. 6. X-ray diffraction patterns of Bi-Te films deposited at 130 (a) and $260{ }^{\circ} \mathrm{C}(\mathrm{b})$, showing the effect of $T_{\text {sub }}$ on the linewidths.
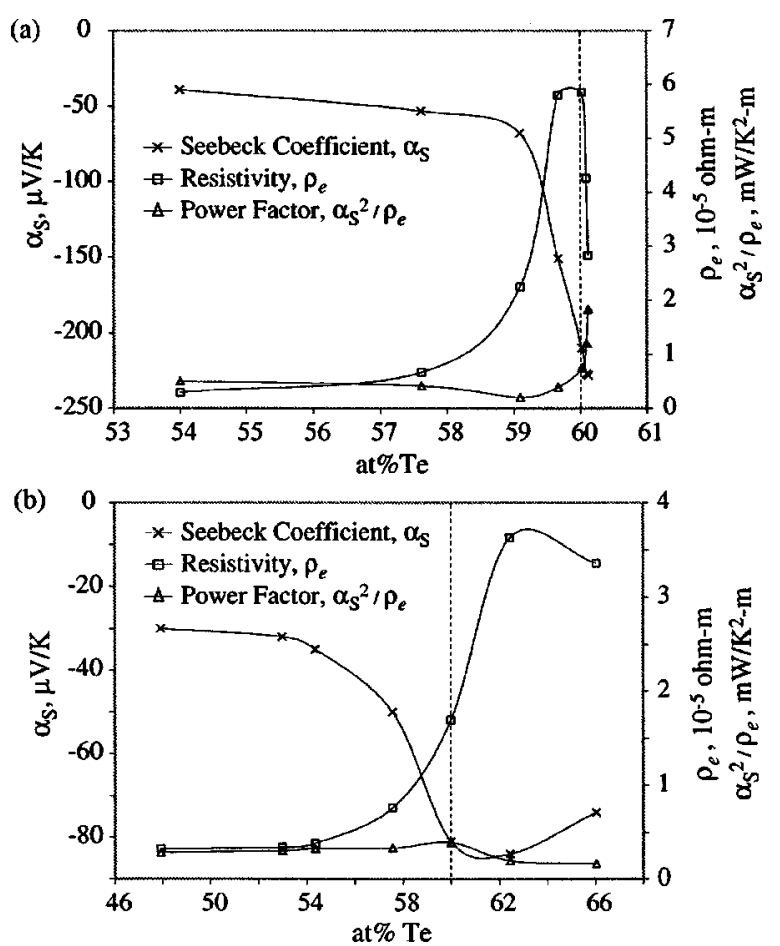

FIG. 7. Effect of Te composition on the TE properties of Bi-Te films deposited on a glass substrate at (a) 260 and (b) $130{ }^{\circ} \mathrm{C}$. (The lines are used only to guide the eye.)

(c-axis for films deposited at $T_{\text {sub }}$ of $260{ }^{\circ} \mathrm{C}$, and random for films deposited at $T_{\text {sub }}$ of $130{ }^{\circ} \mathrm{C}$ ) was observed.

Hall coefficients for films deposited at $260{ }^{\circ} \mathrm{C}$, given in Table II, indicate a reduction of the carrier concentration $n_{c}$ with the increase in the Te content. The mobility $\mu$ has a maximum at at. \% Te of 60 . Note that, although $\mu$ is about ten times lower for the film with at. \% Te of 54, its resistivity $\rho_{e}$ is also lower compared with the film with $60 \%$ of Te, as shown in Fig. 7(a), due to its higher $n_{c}$ ( $\rho_{e}$ is inversely proportional to the product between $\mu$ and $\left.n_{c}\right)$.

The top surface of the films with at. \% Te of 60 and 54 (both deposited at $260^{\circ} \mathrm{C}$ ) is shown in Figs. 4(b) and 4(c), respectively. The film with a larger grain size is richer in Te and has higher carrier mobility. The cross sections are also presented, where this difference in the grain size is clearly indicated by the grain boundaries highlighted with dashed lines.

\section{Effect of substrate material and crystal structure on thermoelectric properties of $\mathrm{Bi}-\mathrm{Te}$ films}

$\mathrm{Bi}-\mathrm{Te}$ films were coevaporated on glass (type-II soda lime), $\mathrm{Al}_{2} \mathrm{O}_{3}$ (0001), $\mathrm{MgO}$ (100), mica, and Pt substrates at $T_{\text {sub }}$ of $260{ }^{\circ} \mathrm{C}$. The effect of film composition on the TE properties is shown in Figs. 8(a)-8(c) for all substrates, with

TABLE III. Measured optimum TE properties of coevaporated Bi-Te films deposited at 260 and $130{ }^{\circ} \mathrm{C}$.

\begin{tabular}{cccccc}
\hline \hline$T_{\text {sub }}\left({ }^{\circ} \mathrm{C}\right)$ & $\rho_{e}(\mu \Omega \mathrm{m})$ & $\alpha_{S}(\mu \mathrm{V} / \mathrm{K})$ & $\alpha_{S}^{2} / \rho_{e}\left(\mathrm{~mW} / \mathrm{K}^{2} \mathrm{~m}\right)$ & at. \% Te & $L_{t e}(\mu \mathrm{m})$ \\
\hline 260 & 28.3 & -228 & 1.84 & 60.11 & 1.0 \\
130 & 16.9 & -81 & 0.39 & 59.99 & 1.3 \\
\hline \hline
\end{tabular}



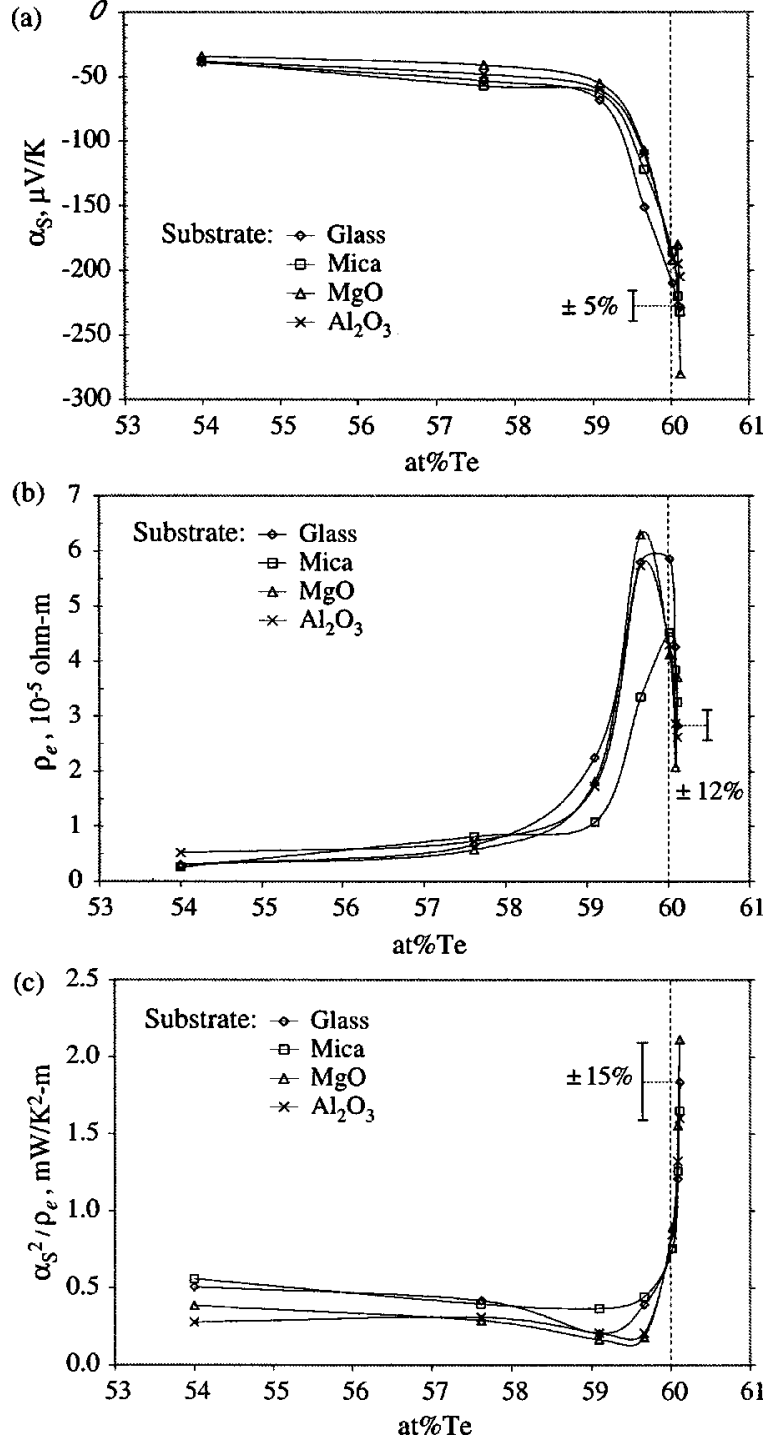

FIG. 8. Thermoelectric properties of Bi-Te films deposited at $260{ }^{\circ} \mathrm{C}$ on glass, mica, $\mathrm{MgO}$, and $\mathrm{Al}_{2} \mathrm{O}_{3}$ substrates. (The lines are used only to guide the eye.)

the exception of $\mathrm{Pt}$ (substrates with high electrical resistivity are required to allow for reliable measurements of TE properties).

At a given at. \% Te, the variation of film composition among the substrates was found to be within $\pm 0.5 \%$. Although the highest power factor was obtained for a film grown on $\mathrm{MgO}$ (at. \% $\mathrm{Te}$ of 60.1), this is not the case for other Te compositions. Therefore, to within an uncertainty of $15 \%$, no significant effect of the substrate (material and crystal structure) on the TE film properties is evident. This is an indication that films grown on Pt are likely to present similar performance as the ones reported here.

In the XRD patterns, the position of the peaks agrees with the associated entries in the Powder-Diffraction File for $\mathrm{Bi}_{2} \mathrm{Te}_{3},{ }^{13}$ for all substrates (including Pt), and no significant effect of at. \% $\mathrm{Te}$ on the crystal structure of the films was observed. The reflection planes verified in the films with at. $\%$ Te around 60 are listed in Table IV, where $l$ is equal to $3,6,15,18$, and 21 . The peaks from the $(00 l)$ planes presented higher intensities. The $c$-axis is the predominant ori-
TABLE IV. Reflection planes of Bi-Te films deposited on various substrates at $T_{\text {sub }}$ of $260{ }^{\circ} \mathrm{C}$ and for at. $\%$ Te around 60 .

\begin{tabular}{ll}
\hline \hline Substrate & $(h k l)$ \\
\hline Glass & $(00 l)+(015)$ \\
$\mathrm{Pt}$ & $(00 l)+(015)$ \\
Mica & $(00 l)+(015)+(0.2 .10)$ \\
$\mathrm{Al}_{2} \mathrm{O}_{3}$ & $(00 l)+(015)+(205)$ \\
$\mathrm{MgO}$ & $(00 l)+(015)+(205)+(1.1 .15)$ \\
\hline \hline
\end{tabular}

entation for the $\mathrm{Bi}_{2} \mathrm{Te}_{3}$ crystal structures grown on glass and $\mathrm{Pt}$, while crystals grown on $\mathrm{MgO}$ are more randomly oriented.

The XRD patterns of the $\mathrm{Bi}-\mathrm{Te}$ film deposited on glass and $\mathrm{Pt}\left(\right.$ at $260{ }^{\circ} \mathrm{C}$ and with at. \% $\mathrm{Te}$ of 60.11 ) are shown in Figs. 9(a) and 9(b), respectively. In (c) is the spectra of the Pt substrate, which should be subtracted from (b), in order to properly compare (a) and (b). Note that the same (00l) peaks are detected in both films, and the relative intensities of most of them are similar.

\section{OPTIMUM POWER FACTOR IN THE ANTIMONY- TELLURIUM SYSTEM}

\section{A. Effect of substrate temperature on thermoelectric properties of $\mathrm{Sb}-\mathrm{Te}$ films}

The measured $\alpha_{S}$ and $\rho_{e}$, and the calculated $\alpha_{S}^{2} / \rho_{e}$ of $\mathrm{Sb}-\mathrm{Te}$ films deposited on glass, are shown in Fig. 10 as a function of $T_{\text {sub. }}$. The tellurium concentration varies from $60.0 \%$ to $61.1 \%$ among the films, which are approximately $1 \mu \mathrm{m}$ thick. The Seebeck coefficient is positive indicating that the films are $p$-type. Note that the maximum $\alpha_{S}$ and the

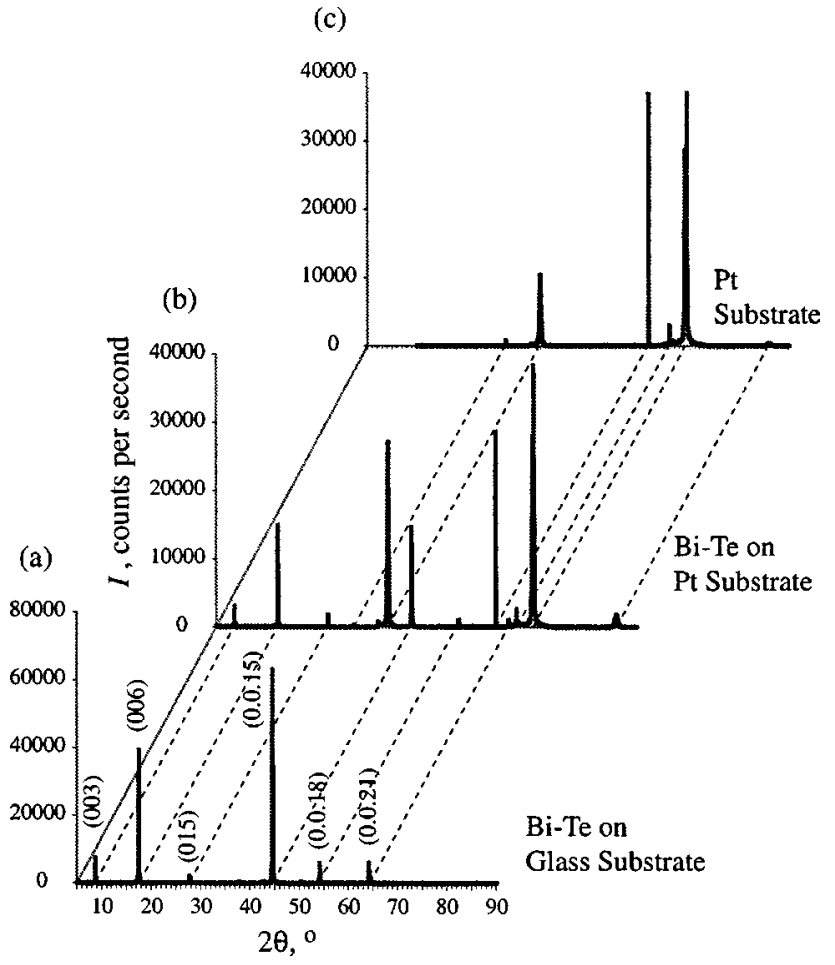

FIG. 9. X-ray diffraction patterns of a Bi-Te film deposited on glass (a) and Pt (b) (at $260{ }^{\circ} \mathrm{C}$ and with at. \% Te of 60.11) and of the Pt substrate (c). 


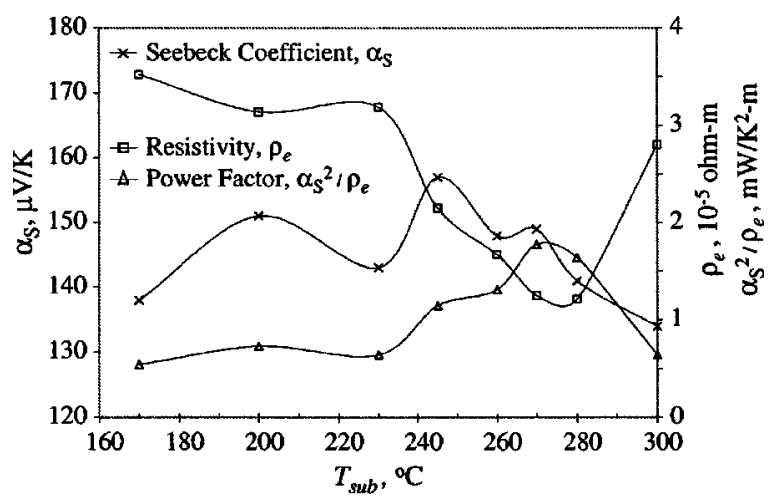

FIG. 10. Effect of $T_{\text {sub }}$ on the TE properties, where the Te concentration (averaged over ten points for each sample) varied from $60.0 \%$ to $61.1 \%$. (The lines are used only to guide the eye.)

minimum $\rho_{e}$ do not occur at the same temperature, as observed for the Bi-Te system in Fig. 3. The optimum power factor is found at $T_{\text {sub }}$ around $270{ }^{\circ} \mathrm{C}$.

For $T_{\text {sub }}<270{ }^{\circ} \mathrm{C}$, the difference between the maximum and minimum $\alpha_{S}$ is about $15 \%$ of their average (Fig. 10), while in the Bi-Te system this value increases to $80 \%$ (Fig. $3)$. This lower sensitivity of $\alpha_{S}$ to $T_{\text {sub }}$ in the Sb-Te compounds can be due to the higher background carrier density of this system compared with $\mathrm{Bi}-\mathrm{Te}$. Because the maximum of the solids curve in the $\mathrm{Sb}-\mathrm{Te}$ phase diagram is shifted towards the side of $\mathrm{Sb}$, crystals of $\mathrm{Sb}_{2} \mathrm{Te}_{3}$ prepared from stoichiometric melts are always $p$-type conductors and contain high concentrations of holes, on the order of $10^{26} \mathrm{~m}^{-3}$ (almost one order of magnitude higher than $\mathrm{Bi}_{2} \mathrm{Te}_{3}$, which is presented in Table II for at. \% Te of 60) ${ }^{14,15}$ Moreover, because the formation energy for antisite defects ( $\mathrm{Sb}$ on the Te sublattice) is low, $\mathrm{Sb}_{2} \mathrm{Te}_{3}$ crystals also contain a high density of such defects.

The lower values of $\rho_{e}$ shown in Fig. 10, when compared with the results from Fig. 3, can also be attributed to the higher background carrier density (or higher $n_{c}$ ) of $\mathrm{Sb}-\mathrm{Te}$ films. As found from Eq. (4), $\rho_{e}$ is inversely proportional to $n_{c}$.

The surface SEM micrographs of the film coevaporated at 170 and $270{ }^{\circ} \mathrm{C}$ are shown in Figs. 11(a) and $11(\mathrm{~b})$, respectively, with magnifications of $60000 \times$ and $15000 \times$ (where the latter indicates homogeneity in the grain structure). The grain size increases with $T_{\text {sub }}$, and an increase in carrier mobility $\mu$ is expected, as discussed in Sec. IV A. This is in agreement with the decrease of $\rho_{e}$ as $T_{\text {sub }}$ increases, observed in Fig. 10, since $\rho_{e}$ is inversely proportional to $\mu$ [Eq. (4)]. At high $T_{\text {sub }}$, reevaporation of Te from the substrate occurs (which creates point defects in the crystal structure), causing the increase of $\rho_{e}$.

The diffraction patterns of powdered $\mathrm{Sb}_{2} \mathrm{Te}_{3}$ single crystal, and the Sb-Te films deposited at $T_{\text {sub }}$ of 170 and $270{ }^{\circ} \mathrm{C}$ are shown in Figs. 12(a)-12(c). The position of the peaks agrees with the associated entries in the Powder-Diffraction File for $\mathrm{Sb}_{2} \mathrm{Te}_{3},{ }^{13}$ and the corresponding reflection planes $(h k l)$ are labeled.

The three highest relative intensities, $I / I_{o}$, reported in Ref. 13, correspond to the planes (015) $\left(I / I_{o}=100\right),(1.0 .10)$ (a)

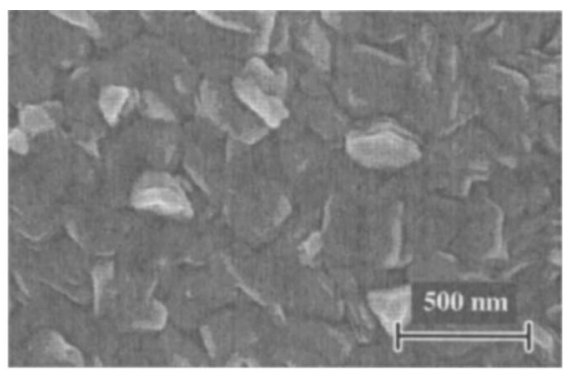

(b)

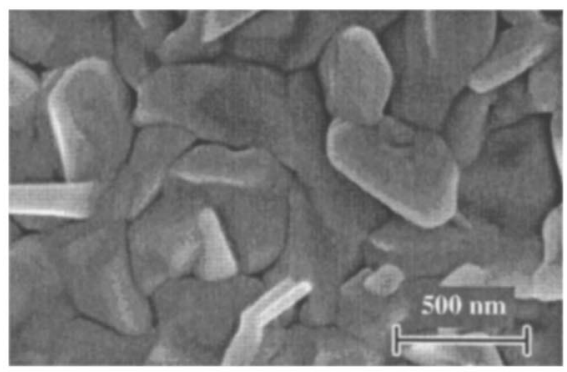

(c)

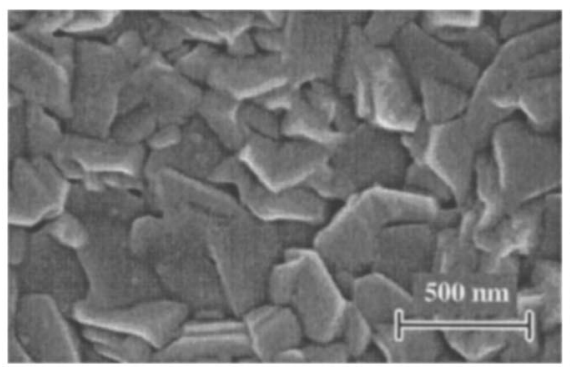

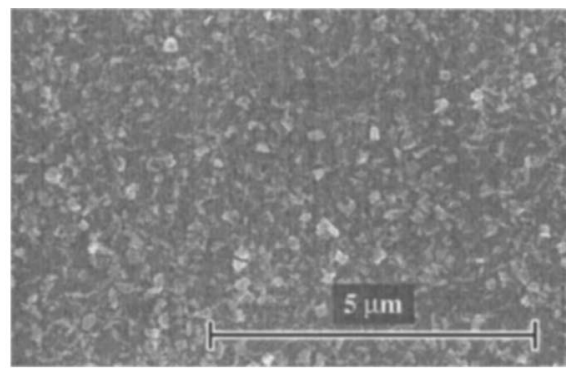
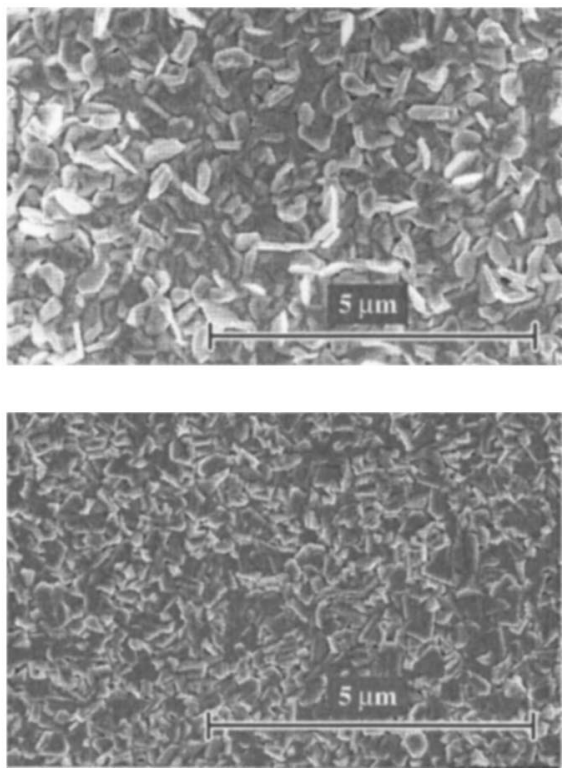

FIG. 11. SEM micrograph showing the top views of the coevaporated $\mathrm{Sb}-\mathrm{Te}$ films deposited at (a) 170 and (b) $270{ }^{\circ} \mathrm{C}$, both with at. $\% \mathrm{Te}$ around 60 , and (c) $270{ }^{\circ} \mathrm{C}$ with at. $\%$ Te about 50. Each micrograph on the right shows a larger area of the same film, indicating uniformity of the grain structure. 


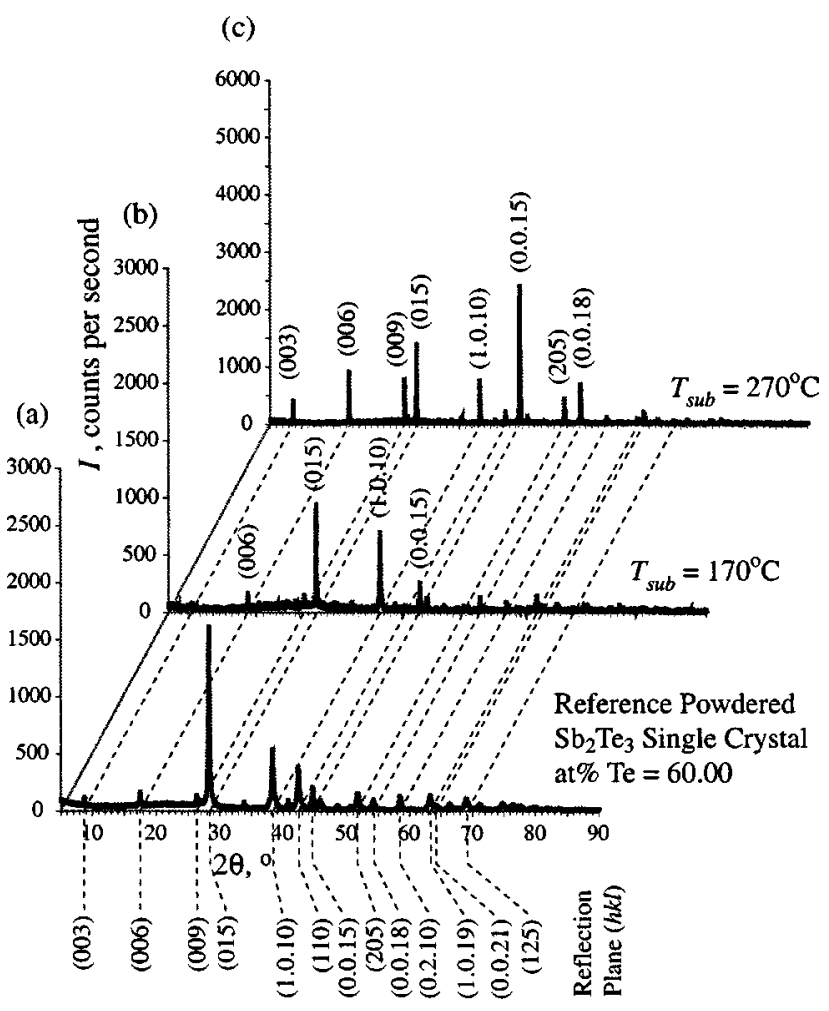

FIG. 12. X-ray diffraction patterns of reference-powdered $\mathrm{Sb}_{2} \mathrm{Te}_{3}$ single crystal (a), and coevaporated $\mathrm{Sb}_{2} \mathrm{Te}_{3}$ films (at. \% $\mathrm{Te} \sim 60$ ) deposited on a glass substrate at 170 (b) and $270{ }^{\circ} \mathrm{C}$ (c). The positions (diffraction angle $2 \theta$ ) of the measured peaks agree with the Powder-Diffraction File (see Ref. $13)$.

$\left(I / I_{o}=35\right)$, and (110) $\left(I / I_{o}=25\right)$. For other peaks $I / I_{o} \leqslant 10$. Note that in Fig. 12, these three strongest peaks are seen in the spectra of the reference-powdered $\mathrm{Sb}_{2} \mathrm{Te}_{3}$ (a) and the two highest peaks are dominant in the film deposited at $170{ }^{\circ} \mathrm{C}$ (b) (the relative intensities are different). These reflection planes indicate no preferential crystallite orientation of samples (a) and (b), which was expected for (a), since the powdered grains are randomly oriented. No convincing match with the X-ray spectra of other possible phases (apart from $\mathrm{Sb}_{2} \mathrm{Te}_{3}$ ) within the $\mathrm{Sb}-\mathrm{Te}$ system was found.

In the XRD spectra for the film deposited at $270{ }^{\circ} \mathrm{C}$ [Fig. 12(c)], and at higher substrate temperatures (not shown here), the intensity of the diffraction peaks that correspond to $(00 l)$ planes increased relatively to the other peaks identified in the films deposited at lower $T_{\text {sub }}$. It is evident that as $T_{\text {sub }}$ increases, the $\mathrm{Sb}-\mathrm{Te}$ crystal structures become more $c$-axis oriented.

In Fig. 13, the XRD spectra of the films deposited at 170 and $270{ }^{\circ} \mathrm{C}$ are enlarged (for $2 \theta$ varying from $37^{\circ}$ to $47^{\circ}$ ) in order to show the difference in the linewidths between the peaks of the two films. As $T_{\text {sub }}$ increases, the linewidths decrease (peaks are sharper), suggesting higher crystalline quality. This result is in agreement with the increase in the grain size shown in Fig. 11, as $T_{\text {sub }}$ increases.

\section{B. Effect of film composition on thermoelectric properties of $\mathrm{Sb}-\mathrm{Te}$ films}

The composition of the $\mathrm{Sb}-\mathrm{Te}$ films was varied from approximately 50 to 62 at. $\% \mathrm{Te}$, and 50 to 74 at. \% Te, for

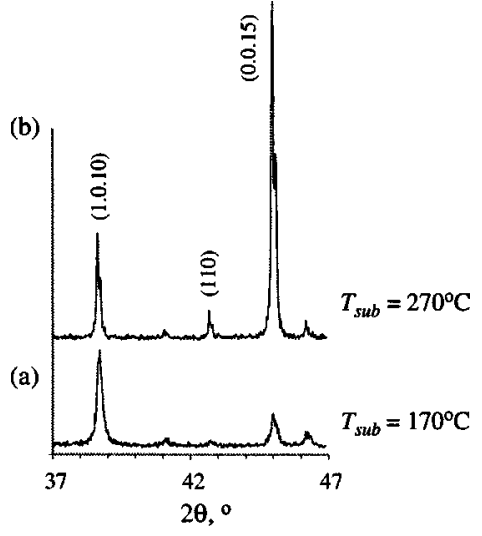

FIG. 13. X-ray diffraction patterns of Sb-Te films deposited at 170 (a) and $270{ }^{\circ} \mathrm{C}$ (b), showing the effect of $T_{\text {sub }}$ on the linewidths.

films deposited on a glass substrate at 270 and $170{ }^{\circ} \mathrm{C}$, respectively. The effect on the TE properties can be seen in Fig. 14. The optimum power factors are given in Table V.

At $T_{\text {sub }}$ of $270{ }^{\circ} \mathrm{C}$, because the measured results do not follow a smooth curve, each property is plotted separately

(a)

(b)

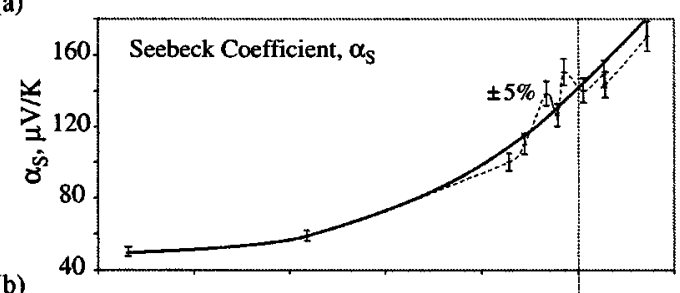

(b)

(c)
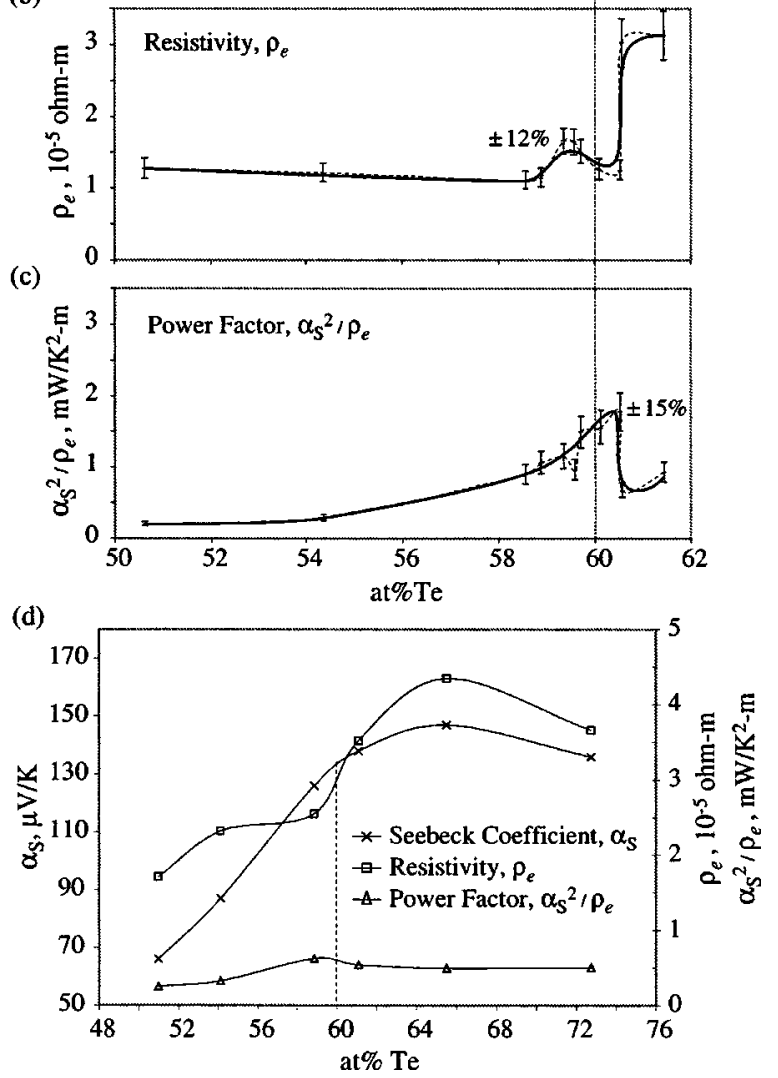

FIG. 14. Effect of Te composition on the TE properties of Sb-Te films deposited on a glass substrate at (a) to (c) 270 and (d) $170{ }^{\circ} \mathrm{C}$. (The lines are used only to guide the eye.) 
TABLE V. Measured optimum TE properties of coevaporated Sb-Te films deposited at 270 and $170{ }^{\circ} \mathrm{C}$.

\begin{tabular}{cccccc}
\hline \hline$T_{\text {sub }}\left({ }^{\circ} \mathrm{C}\right)$ & $\rho_{e}(\mu \Omega \mathrm{m})$ & $\alpha_{S}(\mu \mathrm{V} / \mathrm{K})$ & $\alpha_{S}^{2} / \rho_{e}\left(\mathrm{~mW} / \mathrm{K}^{2} \mathrm{~m}\right)$ & at. \% Te & $L_{t e}(\mu \mathrm{m})$ \\
\hline 270 & 12.5 & 149 & 1.78 & 60.53 & 1.1 \\
170 & 25.5 & 126 & 0.62 & 58.85 & 1.0 \\
\hline \hline
\end{tabular}

with error bars [Figs. 14(a)-14(c)], where an approximate best-fit line is drawn as a guide to the eye. The optimum power factor is found for a film slightly rich in Te. The peak in Fig. 14(c) is located on the right side of the vertical dashed line (which marks the $\mathrm{Sb}_{2} \mathrm{Te}_{3}$ stoichiometry), where the resistivity has a minimum [Fig. 14(b)]. The peak found for $\rho_{e}$ at at. $\%$ Te of 59.5 might be due to a defect structure forming around that composition.

The top surfaces of the films with at. \% Te of 60 and 50 (both deposited at $270{ }^{\circ} \mathrm{C}$ ) are shown in Figs. 11(b) and 11(c), respectively. The one richer in Te has a larger grain size, again indicating that its mobility is likely to be higher. In contrast to the $\mathrm{Bi}-\mathrm{Te}$ system, where $\rho_{e}$ at $60 \% \mathrm{Te}$ was about six times larger than that at 54\% [Fig. 7(a)], the $\mathrm{Sb}-\mathrm{Te}$ system does not show significant differences in $\rho_{e}$ at these compositions [Fig. 14(b)]. The difference in carrier concentration should not be as pronounced as the one measured for $\mathrm{Bi}-\mathrm{Te}$ (Table II), due to the higher background carrier density of the $\mathrm{Sb}-\mathrm{Te}$ films near stoichiometry.

The power factor of the films deposited at $170{ }^{\circ} \mathrm{C}$ [Fig. 14(d)] slightly increases around $60 \% \mathrm{Te}$, and then reaches a plateau. No effect of composition on the crystal orientation of these films is found (they are polycrystalline).

For films deposited at $270{ }^{\circ} \mathrm{C}$, the XRD patterns (not shown here) indicate that at at. \% Te about 60 and above it, the intensities of the peaks corresponding to $(00 l)$ planes increase significantly [the highest corresponding to (0.0.15)]. Below $60 \% \mathrm{Te}$, films are polycrystalline [with the highest peak corresponding to plane (015)].

\section{Effect of substrate material and crystal structure on thermoelectric properties of Sb-Te films}

Additional substrates, such as $\mathrm{Pt}, \mathrm{Al}_{2} \mathrm{O}_{3}, \mathrm{MgO}$, and mica (the same type used in the $\mathrm{Bi}-\mathrm{Te}$ system analysis), were included, together with glass, in each of the coevaporations of Sb-Te, at $T_{\text {sub }}$ of $270{ }^{\circ} \mathrm{C}$, discussed in the previous sections.

All films deposited on $\mathrm{MgO}$ and mica, and most of the films on $\mathrm{Al}_{2} \mathrm{O}_{3}$, had a rather poor quality. The films appeared transparent on these substrates and no electrical continuity was found in them. The exceptions were the films deposited on $\mathrm{Al}_{2} \mathrm{O}_{3}$ at $270{ }^{\circ} \mathrm{C}$, with at. $\% \mathrm{Te}$ of $58.5,58.9$, and 59.3. However, the thicknesses of these three films on $\mathrm{Al}_{2} \mathrm{O}_{3}$ were about $20 \%$ smaller than the values measured for the same films grown on glass (around $1 \mu \mathrm{m}$ ). It is evident that there are problems with $\mathrm{Sb}-\mathrm{Te}$ sticking to these substrates. The crystal structure of $\mathrm{Sb}_{2} \mathrm{Te}_{3}$ is very similar to $\mathrm{Bi}_{2} \mathrm{Te}_{3}$ (rhombohedral with five atoms in the primitive unit cell), ${ }^{16}$ and therefore, we would expect no significant effect of the substrate on the TE properties of Sb-Te films, as verified for the $\mathrm{Bi}-\mathrm{Te}$ system.
X-ray diffraction analyses show that on $\mathrm{Al}_{2} \mathrm{O}_{3}$, the $\mathrm{Sb}-\mathrm{Te}$ crystal structures were strongly $c$-axis oriented, while on $\mathrm{Pt}$, no preferential orientation was detected. Because it was not possible to compare the measured TE properties of the films deposited on glass with the other substrates, and also, because the films deposited on Pt did not have the $c$-preferential orientation verified for the films with optimum power factor deposit on glass, the question remains if the films deposited on Pt will have the same TE properties as the films deposited on glass.

\section{CONCLUSIONS}

For $\mathrm{Bi}-\mathrm{Te}$, the highest power factors were obtained at at. $\% \mathrm{Te}$ around 60 , for films deposited at $T_{\text {sub }}$ of $260{ }^{\circ} \mathrm{C}$ (2.11 and $1.84 \mathrm{~mW} / \mathrm{K}^{2} \mathrm{~m}$ for deposition on $\mathrm{MgO}$ and glass, respectively). Comparing this result with the ones given in Fig. 1, it is verified that the optimum $n$-type film reported by Zou et al. ${ }^{3}$ which was also deposited by coevaporation at $260{ }^{\circ} \mathrm{C}$, presented the same value of $\alpha_{S}$ listed in Table III. However, $\alpha_{S}^{2} / \rho_{e}$ is about two times lower than in Ref. 3, due to the differences in $\rho_{e}$. The $n$-type film reported by Böttner ${ }^{6}$ yielded a lower value of the power factor.

The crystalline quality of the Bi-Te films reported here, deduced from the linewidths of the XRD patterns and from the SEM micrographs, was affected by $T_{\text {sub. No effect of }}$ composition on crystal orientation was seen. Based on the limited number of tests performed, no significant effect of the substrate material and crystal structure on the TE properties was observed, within an uncertainty of $\pm 15 \%$. This is an indication that $\mathrm{Bi}-\mathrm{Te}$ films deposited on Pt are likely to have the same performance as the films deposited on glass, $\mathrm{Al}_{2} \mathrm{O}_{3}, \mathrm{MgO}$, or mica. The XRD pattern indicates that $\mathrm{Bi}_{2} \mathrm{Te}_{3}$ forms on $\mathrm{Pt}$ (at $T_{\text {sub }}$ of $260{ }^{\circ} \mathrm{C}$ ), which supports its use in the connector of the micro-TE cooler, as the metal that interfaces with the TE elements. ${ }^{11}$

The higher carrier concentration of $\mathrm{Sb}-\mathrm{Te}$ films did affect the TE properties. The Seebeck coefficient was found to be less sensitive to $T_{\text {sub }}$ and the electrical resistivities in general were lower, compared with the Bi-Te system. The highest power factor $\left(1.78 \mathrm{~mW} / \mathrm{K}^{2} \mathrm{~m}\right)$ was obtained for a film deposited at $270{ }^{\circ} \mathrm{C}$, with at. $\%$ Te of 60.5 . This result can be compared with the ones reported in Fig. 1. In Ref. 3, the best $p$-type film was deposited at $230^{\circ} \mathrm{C}$ and had $\alpha_{S}^{2} / \rho_{e}$ of $2.8 \mathrm{~mW} / \mathrm{K}^{2} \mathrm{~m}$. This difference in performance is mostly due to $\alpha_{S}$, since the resistivities are comparable, as can be seen in Table V. The $p$-type ternary compound fabricated by cosputtering, ${ }^{6}$ which was annealed after deposition, yielded significantly higher $\alpha_{S}$, but also had a higher $\rho_{e}$ than the other optimum $p$-type $\mathrm{Sb}$-Te films.

The SEM micrographs and the linewidths in the XRD patterns reported here for $\mathrm{Sb}-\mathrm{Te}$ films indicate an increase in the crystalline quality with the increase of $T_{\text {sub }}$. Films deposited at $270{ }^{\circ} \mathrm{C}$ become preferentially $c$-axis oriented for at. $\%$ Te above 60 , while no effect of composition was found for films deposited at $170{ }^{\circ} \mathrm{C}$. Thermoelectric properties were measured only for films on a glass substrate due to the poor quality of the Sb-Te films deposited on $\mathrm{Al}_{2} \mathrm{O}_{3}, \mathrm{MgO}$, and mica. The films grown on Pt were analyzed by XRD and 
showed no preferential orientation, while $c$ orientation was found for optimum films grown on glass. This is an indication that the TE properties of films grown on Pt substrate might also differ from those grown on glass. Due to the limited data, no conclusion can be drawn on the effect of substrate (material and crystal structure) on the TE properties of $\mathrm{Sb}-\mathrm{Te}$ films. A more extensive investigation is needed.

\section{ACKNOWLEDGMENTS}

This work was supported by the Engineering Research Center Program of the National Science Foundation under Award No. EEC-9986866, at the University of Michigan's Wireless Integrated Micro Systems (WIMS) Center, and by the Conselho Nacional de Desenvolvimento Cientifico e Tecnologico-CNPq, Brazil (LWDS). The authors are also thankful to Dr. John Mansfield for the help with the SEM micrographs.

${ }^{1}$ D. A. Wright, Nature (London) 181, 834 (1958).

${ }^{2}$ R. Venkatasubramanian, E. Siivola, T. Colpitts, and B. O'Quinn, Nature (London) 413, 597 (2001).
${ }^{3}$ H. Zou, D. M. Rowe, and S. G. K. Williams, Thin Solid Films 408, 270 (2002).

${ }^{4}$ J. R. Lim, G. J. Snyder, C.-K. Huang, J. A. Herman, M. A. Ryan, and J.-P. Fleurial, Thermoelectric Microdevice Fabrication Process and Evaluation at the Jet Propulsion Laboratory (JPL), Proceedings of the 21st International Conference on Thermoelectrics, Long Beach, California, (2002) (unpublished), pp. 535-539.

${ }^{5}$ H. Böttner et al., J. Microelectromech. Syst. 13, 414 (2004).

${ }^{6} \mathrm{H}$. Böttner (private communication).

${ }^{7}$ T. C. Harman, P. J. Taylor, M. P. Walsh, and B. E. Laforge, Science 297, 2229 (2002).

${ }^{8}$ A. Majumdar, Science 303, 777 (2004).

${ }^{9}$ D. Vashaee and A. Shakouri, Phys. Rev. Lett. 92, 106103 (2004).

${ }^{10}$ L. W. da Silva and M. Kaviany, Int. J. Heat Mass Transfer 47, 2417 (2004).

${ }^{11}$ L. W. da Silva and M. Kaviany, J. Microelectromech. Syst. (accepted for publication).

${ }^{12}$ C. F. Gallo, B. S. Chandrasekhar, and P. H. Sutter, J. Appl. Phys. 34, 144 (1963).

${ }^{13}$ Joint Committee on Powder Diffraction Standards (JCPDS), Powder Diffraction File, Card Nos. 15-874 and 15-863, Pennsylvania (1983).

${ }^{14}$ H. Scherrer and S. Scherrer, CRC Handbook of Thermoelectrics, edited by D. M. Rowe (CRC, Boca Raton, FL, 1995), p. 211.

${ }^{15}$ V. A. Kulbachinskii et al., Phys. Rev. B 52, 10915 (1995).

${ }^{16} \mathrm{M}$. Stordeur, CRC Handbook of Thermoelectrics, edited by D. M. Rowe (CRC, Boca Raton, FL, 1995), p. 239. 